\title{
Fostering Awareness Through Transmediation: Preparing Pre-Service Teachers for Critical Engagement with Multicultural Literature
}

\author{
Xenia Hadjioannou \\ Penn State University-Lehigh Valley \\ U. S. A. \\ Mary Hutchinson \\ Penn State University-Lehigh Valley \\ U.S. A.
}

Research has extolled the potential of transmediation in expanding learners' analytical and critical insight. However, this approach requires teachers prepared to employ this multimodal way of knowing. This study examines the impact of transmediation course experiences on pre-service teachers' comprehension of and critical engagement with multicultural children's literature, particularly in relation to multicultural awareness and social justice; their instructional planning; and their intended practice. Findings suggest presenting and supporting transmediation as a critical literacy approach can have a powerful effect on pre-service teachers' understanding of texts, on their sensitivity to diversity issues, and on their beliefs about teaching and learning.

The Potential of Transmediation

Teaching a Transmediated Curriculum

Methodology

Findings

Discussion

Study Limitations and Implications for Further Research

Conclusion

References

A major pedagogical challenge is to bring knowing to the surface of consciousness, to help students render knowledge as material culture; in other words, to help them transform what they know, remember, sense, feel, and believe into a paragraph

of writing, a lively dialogue, or a scrapbook of images.

Pippa Stein (2000, p. 333)

$* * * * *$ 
We live in a world replete with opportunities to engage our senses and interpret our perceptions in ways that are significant to us. This meaning-making process is an important aspect of personal development, but it is also a crucial aspect to literacy development in educational settings, particularly in today's multicultural, multilingual classrooms. Recognizing this, the Australian Curriculum Assessment and Reporting Authority positioned multimodality prominently in the 2012 Australian Curriculum for English, stating that texts "can be written, spoken or multimodal" and calling for students to "learn about the different ways in which knowledge and opinion are represented and developed in texts, and about how more or less abstraction and complexity can be shown through language and through multimodal representations" (ACARA, 2012). Similarly, multimodal communication is identified as a "key competency" that adds "new basics" in the diversity-focused New Zealand National Curriculum (New Zealand Ministry of Education, 2008). However, despite the increasing presence of the notion of multimodalities in some formal curricula and educational policies, literacy development in many schools is often presented as "autonomous skills of knowing how to encode meaning in linear ways through printed text" (Winters, 2010 , p. 1). Although valuable, this approach relies heavily on proficiencies often foreign to contemporary diverse student populations whose ways of learning "are in direct opposition to the mindsets underpinning traditional systems of education" (Black, 2008, p. 583). Because of and in reaction to this linear emphasis, researchers have begun to encourage classroom practice that is less dominated by a focus on students' reading and writing skills but instead integrates the expansion of students' multimodal ways of knowing. This pedagogical approach has been examined by a variety of scholars who have called into question dominant classroom practices that offer a narrow, languagebased approach to becoming literate, which often fails to meet the needs of a diverse student body (Akintunde, 2007; Dyson, 1986, 2004; Exley \& Mills, 2012; Semali \& Fueyo, 2001; Serafini, 2010; Short, Kauffman \& Kahn, 2000; Siegel, 1995, 2006; Suhor, 1984; Tierney, 2009; Tierney, Bond, \& Bresler, 2006; Whitin, 2006; Winters, 2010). Many of these researchers view transmediation as a practice that has the capacity to meaningfully engage students with semiotic objects other than language-based texts and to involve them in critically examining the culturally-laden norms of semiosis in different systems (Siegel, 1995). As such, transmediation appears particularly promising in supporting multicultural education through fostering critical awareness of values and biases underpinning conventions (e.g., why has the masculine grammatical gender been traditionally considered the "unmarked" form?) and of author/sign creator choices (e.g., why are the Taino people encountered by Columbus rarely identified by their tribal affiliation in children's books depicting this first contact?)

However, the paradigm shifts required for implementing such an approach can only happen if we have teachers who have experienced this approach themselves and who are prepared to engage in this multimodal way of knowing with their students. In this paper, we heed Lowenstein's (2009) call for systematic study of a new paradigm of multicultural pre-service teacher education by closely 
examining the implementation of transmediative activities with pre-service teachers in the context of multicultural children's literature.

\section{The Potential of Transmediation}

According to Siegel (1995), transmediation is "the process of translating meanings from one sign system (such as language) into another (such as pictorial representation)" (p. 456). The concept was first introduced by Suhor (1984) who argued that the movement across sign systems "stretch[es] the receptive and productive capacities of the students" (p. 254). Furthermore, Siegel (1995) asserts that transmediation is a fundamentally generative process, as individuals mediating across modalities must not only utilize their understanding of the different media involved, but also correlate between content and representation and reconceptualize and recast a semiotic object in an altered form.

Short, Kauffman, and Kahn (2000) note that this is a familiar practice to learners who constantly move across sign systems in their daily lives as they sprinkle their text messages with emoticons and post spoofs of pivotal media moments on YouTube, reaching new insights in the process. Transmediation captures multimodal ways of knowing that allow students to express their knowledge and understanding in forms that have meaning to them (Semali \& Fueyo, 2001) and "promotes the generation of new ideas potentially unavailable in other sign systems" (Loretto \& Chisholm, 2012, p.140).

Transmediation can be a powerful tool in literacy education, as it can open up the interpretive possibilities of written texts, which are the principal type of semiotic object in language arts classrooms, in three ways: (a) by engendering multiple alternative interpretations and perspectives; (b) by allowing students to recast texts in personally meaningful literacies and modalities; and (c) by "encouraging students to use texts as 'thinking devices'... that can be analyzed and interpreted by drawing on multiple literacy practices" (Loretto \& Chisholm, 2012, p. 140). Such interpretive endeavors can become fertile grounds for questioning social norms, power relations, and "the social construction of the self" (Shor, 1997, p.2). In the process, natural connections are established in general between transmediation and critical literacy (Albers, Holbrook, \& Harste, 2010; Semali, 2002) and in particular between transmediation and critical media literacy (Napoli, 2002; Semali, 2002) and multicultural literacy (Banks, 2003; Kellner, 2000). Albers, Holbrook, and Harste (2010) assert that transmediation supports critical reflection, whereas Siegel (1995) describes it as a fundamental component of inquiry-based classrooms. Additionally, transmediation is understood as a tool that invites critical considerations that can support conversations about class, race, and gender (Semali, 2002) and that can facilitate the de-otherization of oppressed groups. These multiple, multicultural literacies help students gain the requisite competencies for working in a participatory and democratic society (Kellner, 2000; Winters, 2010) and "view 
knowledge from diverse ethnic and cultural perspectives, and...use knowledge to guide action that will create a humane and just world" (Banks, 2003, p. 18). Transmediative teaching and learning can offer this development and provide both learners and teachers with a powerful pedagogy for engaging and interacting with society.

Given this potential, transmediation appears to be well poised to facilitate critical examinations of literary text in general and multicultural literature in particular, since mediating across sign systems can help illuminate such textual elements as underlying values of the text creator(s), hidden biases, and cultural symbols, as well as the values, biases, and cultural lenses of the readers themselves.

\section{Teaching a Transmediated Curriculum}

Transmediation moves the curriculum away from a "verbocentric ideology" to one that is generative, providing students with numerous avenues for displaying what they know and understand and stations "students as knowledge makers and reflective enquirers" (Siegel, 1995, p. 473). A natural fit for inquirybased approaches, transmediation can introduce students to a variety of discourses, while at the same time providing legitimate spaces in school learning for the representational resources students bring with them to school.

Transmediation is equally powerful for teachers as it allows them to see student learning manifest itself in multiple ways (Akintunde, 2007). However, in order for transmediation to reach its full potential as a tool for critical literacy, educators must be able to recognize, understand, and apply transmediative teaching, as naïve implementations can trivialize transmediation and delegate it to the status of a "curricular ornament" (Siegel, 1995, p. 473). A useful conceptualization in this endeavor is the distinction between literal and imaginative transmediations (Suhor,1984): literal transmediations involve conceptually straightforward translations such as eating a food described in a story or reading a text out loud, whereas imaginative transmediations are more cognitively demanding because they involve the creation of new content such as writing a poem in response to a painting or dramatizing a scene implied but not described in a narrative. Though the former are not devoid of value, the latter appear to be better equipped to "extend the potential meaning" of semiotic objects and stretch the capacities of the students (Loretto \& Chisholm, 2012, p. 140).

Despite its paradigm-shifting potential, transmediation is still in its infancy in many instructional settings where it is often viewed as a pedagogy on the fringes. Indeed, as Tierney (2009) laments, the talk of new literacies in US schools far exceeds their presence. The reasons for this lack of adoption are many. Siegel (1995) believes that transmediation is a threat to the dominant, linear way of knowing that privileges "the display of received knowledge over 
critical and creative thinking" (p. 473). Additionally, Short, Kauffman, and Kahn (2000) believe educators are uncertain about this pedagogy because of their lack of exposure to it in their own learning.

Nevertheless, researchers believe that if educators are presented this approach, transmediation can gain a prominent place in teaching and learning. According to Siegel (1995), the importance of providing this kind of development is crucial if we are to move toward a consideration of "curricular possibilities that do not marginalize other ways of knowing" (p. 457). This adoption process begins in pre-service preparation programs where transmediation can be introduced, experienced, and examined for its potential to "contribute to learning opportunities in ways that support complex and collaborative engagement with problems and issues, projects and topics, process and product, [and] inquiry and discussion" (Tierney, Bond, \& Bresler, 2006, p. 360) and to help students "explore constructing models of meaning making that address growth, evolution, sustainability, and intervention" (Tierney, 2009, p. 338).

\section{Methodology}

This research examined the implementation of transmediation as a tool for fostering critical engagement with multicultural literature within the context of literacy methods coursework for pre-service teachers. Specifically, we examined how prospective elementary-level teachers learned about transmediation by engaging in a series of in-class transmediative activities with multicultural children's books, and we sought to trace the potential impact of this engagement in the pre-service teachers' instructional planning and intended practice. This inquiry was pursued through qualitative case study exploring the following research questions:

1. How did participation in transmediative activities improve, if at all, the pre-service teachers' comprehension of multicultural children's books?

2. How did participation in transmediative activities influence, if at all, the pre-service teachers' critical engagement with multicultural children's books?

3. How, if at all, did participation in transmediative activities impact the pre-service teachers' instructional planning and intended teaching practice?

The delimited nature of this study dictates a methodology that affords close and exhaustive examination of a bounded instance through a variety of vantage points as Stake (1995), Yin (2012), and Merriam (1998) recommend for case study. Therefore, a qualitative case study approach was employed. According to Dyson and Genishi (2005), researchers seeking to explore the "messy complexity of human experience" as that is enacted within a specific social unit (in this case, literacy methods classes) are often led to the use of the case study methodology because "detailing of local specificity" (p. 3) affords 
insight into complex, abstract phenomena such as comprehension of and critical engagement with multicultural children's books and impact on intended teaching practice. Even though case studies do not yield findings generalizable to a population in ways akin to large-scale quantitative studies (Morse, 1999), wellexecuted case studies are characterized by extensity (Webb, 1961), as the casederived theory is "applicable beyond this immediate group and is applicable to all similar situations, questions, and problems, regardless of the comparability of the demographic composition of the groups" (Morse, 1999, p. 5).

\section{Participants and Institutional Context}

The participants in this IRB-approved study were 21 pre-service teachers enrolled in a five-course block of junior-level methodology courses (known as the language and the arts block), which includes reading methods, writing methods, children's literature, arts methods, and music methods. The participants enrolled in this block over two consecutive semesters: 7 in the first semester and 14 in the second. Five of the participants were male and 16 female. Also, with the exception of one African American woman, all participants were White. During the informed consent process, potential participants were notified that participation in the study involved allowing the researchers to observe their class participation and to make digital copies of artifacts they would be producing as part of their regular course activities and course expectations. Potential participants were assured that participation was strictly voluntary and that a decision not to participate or to withdraw participation at a later point would not adversely influence their course grades.

The study participants' teacher preparation program is housed in a small urban/regional campus in the northeast United States, though it is part of a sizeable multi-campus university. The program design places students in cohorts during their junior year, after which point they "travel" together. Their first cohortbased block of courses is the language and the arts block. For the purposes of this study, we examined a series of course experiences related to transmediation during this block of courses, particularly those deployed in the three literacy methods courses (reading, writing, and children's literature). The first author of this article (a recent immigrant to the United States, who has been teaching language and literacy courses at the college level for over 10 years) taught three courses, using an integrated three-course syllabus that sought to highlight the natural connections across the three courses. The second author, who became involved with the study after the data collection was completed, is an ESL (English as a Second Language) educator and has been teaching at the college level for over 20 years. Both researchers are committed to multiculturalism, critical citizenship, and social justice. Through the study, we (both researchers) remained acutely aware of the potential bias in conducting qualitative research and particularly in examining one's own practice. We made bracketing (Gubrium \& Holstein, 1997) efforts to keep values and assumptions in check both when 
collecting data and when interpreting the behavior of study participants (Ahern, 1999).

\section{Data Collection and Analysis}

The thorough, in-depth study of a bounded instance involved in case study research requires the use of several data collection sources and instruments that have the capacity to highlight different aspects of the case and ascribe validity to the research through triangulation. For the purposes of this study we utilized the following data sources:

1. Observation Data: Transmediation was addressed in several in-class sessions involving participation in transmediative activities; reflective discussions on transmediation, its meaning, and pedagogical value; and curricular planning for transmediation. The literacy methods course instructor took field notes during the sessions. Of prominence within these field notes were (a) a four-hour session during which the pre-service teachers engaged in collaborative transmediative activities in response to multicultural children's books and (b) a workshop session on transmediative instructional planning.

2. Transmediative artifacts: During the session described above in (a), the study participants produced several collaboratively created artifacts such as posters, collages, poems, photographs, and video clips. The researchers created and collected digital copies of these artifacts.

3. Post-activity reflection papers: At the end of the four-hour session, participants were invited to do a quickwrite (Rief, 2003) reflecting on their experience with the session activities.

4. Transmedia projects: As part of their grade-bearing obligations, study participants had to select a multicultural children's literature book and create a set of instructional materials, which would engage elementary students in critical literacy-promoting transmediative activities. The assignment also included a reflection paper asking students to explain how their instructional plans intended to transform the text and open it to new thinking or interpretation through the use of various media. The submitted assignments were used as data for the research.

The data were coded originally following an open-coding approach and, subsequently, using focused coding: a process that, according to Dyson and Genishi (2005), allows researchers to approach their data inductively rather than imposing onto it predetermined conceptual frameworks. During the open-coding phase, the written data (field notes, post-activity reflection papers, and transmedia projects) and the artifact data (transmediative artifacts) were scrutinized repeatedly to describe how the pre-service teachers engaged with the children's books and how transmediation was featured in the instructional materials they produced and the reflections they wrote. During the focusedcoding phase, the codes produced through open coding were reconsidered with 
the intention of producing progressively abstract conceptual constructs, with a particular focus on topics of the three research questions (improved comprehension, critical engagement with literature, and influence of transmediation in intended practice).

\section{Findings}

As mentioned in the methodology section, as part of their experiences in their literacy methods courses, the pre-service teachers were introduced to transmediation and provided with a model of critical literacy pedagogy (Beck, 2005; Lewison, Flint \& Van Sluys, 2002). Prior to this introduction, the class had spent time discussing multicultural children's literature, reading exceptional books representing diverse perspectives, and examining the complex issues of cultural authenticity, bias, privilege, and stereotyping. The formal introduction to transmediation commenced with a short lecture on such key terms as media, modality, semiotics, and transmediation. This was followed by an extensive period of collaborative engagement with transmediative activities pertaining to multicultural storybooks. During the period of collaborative engagement, the preservice teachers were divided into groups of three to four individuals and were given one of two storybooks:

- Love as Strong as Ginger, written by Lenore Look (1999) and illustrated by Stephen Johnson: In this book, inspired by the author's memories of her grandmother (GninGnin), Look tells the story of a young girl who spends a day with her GninGnin at the crab cannery where she works.

- Hannah is My Name, written and illustrated by Belle Young (2004): Based on the author's own immigration story, this book is about $\mathrm{Na}$ Li/Hannah and her family who moved to the United States and live with the fear of getting deported while they are waiting for their green cards to arrive.

Selected for having received high praise in such authoritative children's literature reviewing venues as the Horn Book Guide and Children's Literature, these books were noted not only for their literary quality, but also for their nuanced and poignant depictions of immigration, which suggested a potential to engender and support critical conversations about race, cultural hegemony, and social justice.

Beyond receiving a storybook, each group was also given a set of activities and was invited to work thoughtfully through as many of them as the allotted time would allow. To allow space for multiple interpretations that could engender contemplative discussions, the instructor chose not to provide any further introduction to the books or the activities. However, as illustrated in the section on Critical Engagements with Multicultural Literature (below), she did insert her voice into group conversations when responses stayed in shallow interpretive waters. The activities were designed to fall within Suhor's (1984) 
imaginative transmediations and aimed to impel the pre-service teachers to think critically about the books. For example, for Look's (1999) Love as Strong as Ginger, the pre-service teachers were asked to examine race relations in the book and to create a visual representation of their findings. Similarly, one of the assignments for Young's (2004) Hannah is My Name reads: "Imagine that, instead of helping Baba [dad] and Hannah, the doorman [whom Hannah always feared] had led the immigration officer in the diner [where Baba worked] and, pointing to them, had said: 'Here are the illegals. Arrest them!' Dramatize the scene, rehearse it and record it."

The pre-service teachers were given ready access to various materials including colored construction paper, colored pens, markers, crayons, scissors, tape, cameras, flip cameras, laptop computers, and printers and were asked to use them in any way they saw fit. The groups were allowed to work at their own pace and to move on to other activities once they were done with the first. During the collaborative engagement period, the instructor circulated among the groups listening in on conversations, answering clarification queries, and, on occasion, asking questions aiming to challenge group members and push them toward more sophisticated, critical engagement with the text. At the end of the session, the participants were invited to present the artifacts they had created and participated in a debriefing conversation about their experience. In subsequent sessions, the class continued to talk about transmediation in the context of critical literacy and worked on developing transmediative instructional materials. The following findings are analyzed in light of the three research topics: improved comprehension, critical engagement with literature, and influence of transmediation in intended practice.

\section{Improved Comprehension}

Improved comprehension of the books appeared to be one of the most prominent results of engaging in transmediative activities. Through the open- and focused-coding process, three themes emerged from both the observation data and the reflective writings: more in-depth understanding of the story, stronger empathy with the characters and their plight, and the challenge inherent in moving beyond the typical reader-response analysis of more traditional assignments.

More in-depth understanding. In their reflections, almost all of the preservice teachers stated that the transmediative activities had helped them understand the books at a much deeper level. This claim verified the instructor's observations, since she frequently witnessed comprehension "a-ha!" moments from several groups as they were working. For one of the groups working on Look's (1999) Love as Strong as Ginger, such a moment came while creating a visual representation of the narrator and her grandmother: 
"Ha! Did you notice how the smells change as [the two main characters] move from the crab factory to the grandmother's kitchen?" one of the students exclaimed. "The kitchen is the grandmother's domain," another added. "This is where she shines. Where she can pour all her love for this little girl in her cooking; where she gives her what she will need to fulfill the whole family's dreams," the first student explained. Picking up the thread, a third student chimed in, "The hard work, the food... It's all for the little girl. She is the one with the true chance and the grandmother is willing to give it all for her to have it." As her teammates nodded, the student turned to the instructor who happened to be near by, "You know, I did not like this book when we first read it. I was like 'Blah, blah they are working, they are cooking, so what?' I still don't love the book, but now that I get it more, it's not that bad."

This more sophisticated level of comprehension was particularly important to some students who felt that they were not necessarily strong readers. The reinvention of their understanding of the story through transmediation reinforced what happened in the book and helped them not only remember it, but also reevaluate it with greater intensity. As one student stated, "We were in a way forced to look beyond the surface and to connect the symbols to text that supported our claim." These new perspectives of seeing the print text through another medium had the greatest impact on their comprehension as they ended up rereading the written text and analyzing the illustrations multiple times in order to transform their understanding into a final product. As one student stated, "Engaging in the [transmediation] activity helped me feel more connected to the text."

Empathy for characters. Another theme that emerged was that the preservice teachers developed a greater sense of empathy for the characters, which is a crucial component to the process of de-otherizing individuals whose backgrounds and experiences are different than one's own (Nieto, 2005). The participants seemed not only to relate to the plights of each character more deeply, but also to apply this understanding to their own lives. As one student stated, "The activity forced me to think about the characters as if they were real people and [to] try to understand their motivations."

In addition, the empathy developed through the process opened up aspects of the story that may not have been apparent in just reading and responding to the text. An interesting example of empathy-building came from a group working on Young's (2004) Hannah is My Name: in the video-recording of an imagined scene in which the young heroine and her father are pursued to be arrested for their status as undocumented immigrants, a pre-service teacher playing the role of Hannah could be heard laughing. During the debriefing conversation at the end of the session, the young woman volunteered: "During the video part, I was laughing - not because I was not taking this seriously. No. I was so upset imagining how horrible such a thing would be for this little girl and 
her family that this nervous laughter came out. I could not control it. I'm still very upset."

Intellectual challenge. For some pre-service teachers, the transmediation project was a welcomed alternative to the typical "verbocentric" tasks in most reading/writing classrooms. It permitted them to access artistic and imaginative strategies they would not necessarily have tapped into in a more traditional assignment and to express themselves in ways that were important to them as they showed their comprehension of the stories. In the reflections, many commented on how the transmediation project was "enjoyable" and offered a "creative" means of interpreting the story, which allowed them to "understand and relate to it better than if [they] had just read it and had a short discussion about it." However, several also noted the difficult nature of such an alternative assignment.

I felt that using other mediums of expression allowed for some connections to the core aspect of the book, if not the characters in general, but it also provided for some challenging work that required a level of deep thought or empathetic correlations that I didn't really possess at the time.

\section{Critical Engagement with Multicultural Literature}

According to Semali and Fueyo (2001) and Albers, Holbrook, and Harste (2010), transmediation can be a powerful gateway toward critical engagement with texts and other semiotic systems. The second research question examined whether participation in transmediative activities would impel the participants to engage in critical analysis of the multicultural literature texts.

Observations during the in-class session on transmediation suggested an interesting pattern of progressive critical engagement with multicultural literature. As the groups of pre-service teachers began working on the transmediative activities, their attitude was one of light-hearted naïve engagement. For example, in the context of an activity related to Young's (2004) Hannah is My Name, the pre-service teachers had to create visual representations of elements that presented positive aspects first of the United States and her culture and subsequently of China and her culture (the home country and culture of the book's heroine) and compare those two representations. All four groups that picked this activity began by combing through the book to identify such elements and then proceeded to create posters or collages on construction paper encompassing literal (e.g., dress) and symbolic (e.g., a mountain representing difficulties faced but overcome) cultural elements. However, as the groups got deeper into the activity and started to consider the task of comparing their findings, they invariably started treading critical thinking paths: the comparison brought forth the realization that their US poster was significantly more dense, 
multilayered, and positive than the China poster which was sparse and presented nostalgic images. For three of the four groups, the conversation was drawing to a close on that conclusion, until the instructor stepped in to ask, "Why the difference?" After quickly sidestepping simplistic explanations (e.g., "It's because they are happier/freer/better off here"), the groups engaged in significant discussions regarding Young's values and intentions, as well as their own biases. Often these conversations developed into discussions about the UScenteredness of literature produced and published in the United States and the intentional or inadvertent marginalization of other cultures. In the end, one group even decided to discard their original posters and replace them with a single poster whose entire surface was taken up by a collage of the US flag with the star formation of the Chinese flag appearing enclosed in a circle in a small section in the upper right hand quadrant of the US flag (see Figure 1). When explaining this decision, they stated that this represented the diminished, almost fading presence of China in the book, the privileging of US culture in the publishing industry, but also "the way we [Americans] want immigrants to be," meaning mostly American with just a hint of their native culture.

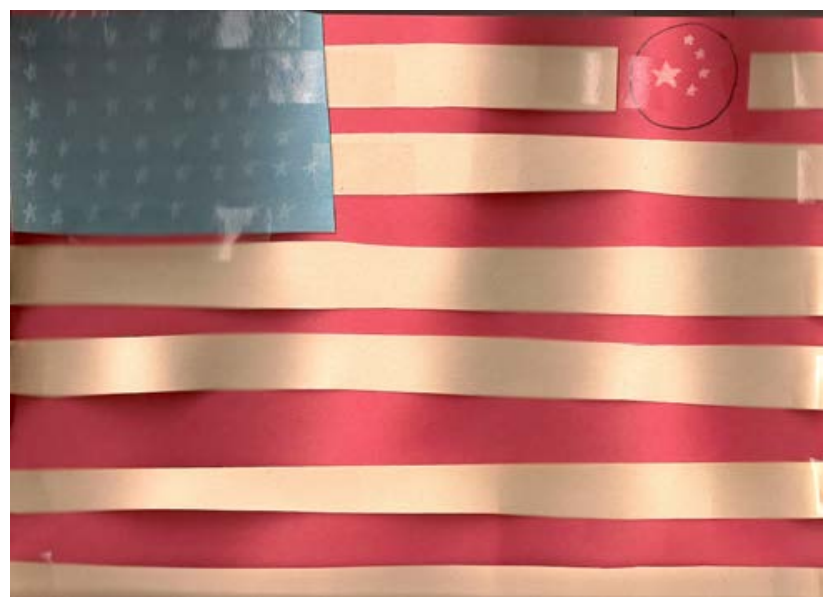

Figure 1. Collage representing the presence of US and Chinese cultural elements in Young's (2004) Hannah is My Name.

Similarly, when working on an activity asking them to use a camera to capture race relations as those are depicted or implied in Look's (1999) Love as Strong as Ginger, both of the groups that had picked the activity were initially puzzled by the question. After examining the book more closely, one of the groups honed into GninGnin's statement regarding her physically taxing job at the crab cannery: "'Only job I could find,' she said. "Nobody wants to hire an old woman who can't speak English"' (Look, 1999, n.p.). The group imagined GninGnin's early days in America and the series of rejections she must have faced by employers when trying to secure employment and decided to depict one of the rejection scenes. In staging the scene, the group decided to have GninGnin hold a misspelled sign "Ned Gob wil work 4 fud" to indicate that, since 
GninGnin did not speak any English, she had relied on some other member of the Chinese immigrant community who spoke (and wrote) some English to help her communicate her need for a job to potential employers. They also resolved to present the "potential employer" to look taller and laugh derisively at GninGnin, who appeared sad and cowering. In addition, after a bit of a debate, the group decided to add "Non English speakers Need not apply" on the "Help Wanted" sign appearing in the photo. Other students in the group objected to this interpretation, feeling that "people would not write that." However, others felt strongly that "even if they don't write it, they think it! So it belongs there," which in turn led to a discussion about language stereotypes and bigoted language.

Interestingly, the second group also spotted the same quote. However, they quickly dismissed it as "simply a statement about language" and maintained that position even after the instructor's probing. After encountering the first group's interpretation during the sharing portion of the session, one of the members of the second group wrote in her reflection, "I see now what the other group was able to pull out, but we truly didn't see any racism."

Ultimately, it can be said that, though not every single activity encouraging a critical interpretation accomplished that for every group, all of the participants did engage in at least one activity that furthered their critical reading of the book. Curiously, however, unlike enhanced comprehension, which was prominently featured in the reflections of all study participants as a significant benefit of transmediation, the issue of critical interpretation was only discussed by a few. Some participants noted how transmediation got them to consider the "underlying values" in print text and illustrations, and some expressed concern about the lack of balance in presenting more positive aspects of a culture or character.

\section{Instructional Planning and Intended Teaching Practice}

Following the in-class work on transmediation, the pre-service teachers were expected to produce instructional materials featuring critical literacypromoting transmediative activities. The process of constructing such materials appeared to challenge the pre-service teachers who often approached the instructor with frustration over what they understood to be inadequate drafts that invariably featured "literal" transmediative activities (Suhor, 1984). Commonly, the pre-service teachers would initiate the discussion by saying, "I get how what we did in class pushed us to think more deeply and critically, but when I try to do it, it just doesn't do that." This prompted the instructor to invite students to bring in drafts of their instructional planning project for a workshop session, which was a common process for the courses under study. During the session, the preservice teachers shared their drafts with each other and the instructor and gave and received feedback on their work. Some groups were able to push each other to critical thinking territory without too much support by the instructor, whereas others required extensive conversations with the instructor before abandoning literal transmediations that merely "illustrated or decorated the text" (Loretto \& 
Chisholm, 2012, p.140). Ultimately, with the support of the instructor and of each other, most pre-service teachers moved to more "imaginative" activities and produced materials that adequately met the assignment criteria (Suhor, 1984).

The participants' final reflections about their transmediative lesson plans offered insights into their understanding of how these activities could be used in the classroom and the potential impact it might have on students themselves. For many of the pre-service teachers, it was easy to see the connections between their own experience with transmediation and the application of this process in the classroom. The comments were generally positive as they worked to deconstruct a lesson and reconstruct it in this new environment. They discussed how the experience helped them to "stretch" their minds in order to incorporate multiple modalities into the lessons. One participant found that the experience offered an opportunity "to truly experience the rigors of being an elementary classroom teacher" and to move beyond a lecture-based approach with "basic student interaction." This is an important realization for pre-service teachers who often have limited exposure and understanding of the challenges inherent in teaching language arts.

The process, however, was not without its struggles. Their reflections indicated that the pre-service teachers learned firsthand the demands required to incorporate substantive transmediative activities into lessons. Many of them alluded to the difficulty in trying to "figure out" what to include in the plans without ending up with a cluster of frenetic and disconnected components. The need to "narrow" the focus of the lesson and to choose meaningful activities rather than "trying to fit everything in" became quite evident as they worked their way through building these lessons.

As far as the impact of transmediative activities on student learning, the participants' reflections often mirrored the effect these activities had on themselves as learners. Many of them referenced how much more students might be "connected to a text" because they were seeing it at a deeper level. They also felt that the incorporation of music and art to encourage text analysis helps the students not only "think critically," but "showcase their individual abilities." Some referenced learning styles and expressed that "incorporating listening, discussion, music, art, and writing" provided an opportunity for all students to "find at least some part of the lesson enjoyable and engaging." Overall, there appeared to be agreement among the pre-service teachers that transmediation "is an effective way to get the students completely involved and excited about learning."

In addition, some participants noted that the benefits of transmediative activities might extend beyond the language arts classroom and encourage students to become more active learners in other subject areas. As one preservice teacher stated, "When students are able to practice talking to their peers about their interpretations of the text, they will be able to express themselves better in other activities and class discussions." Many of them also were able to identify the cultural impact of transmediation, finding that the students can "learn to appreciate new ways of thinking about other cultures...[and] to respect that 
other cultures can be different or similar to their own." These cultural connections and understandings are important, not only for students but for these future teachers as well, who will be called upon to offer a language-rich, multicultural curriculum for today's diverse learners. Transmediation offers this pathway because, as one pre-service teacher offered in summary, "the students are really going to have to think."

\section{Discussion}

In this study, we examined how work with transmediation impacted preservice teachers' comprehension of and critical engagement with multicultural children's literature and how transmediation featured into their instructional planning and intended teaching practice.

Our findings confirm assertions by other researchers that transmediation can function as a tool for fostering complex literary thinking and enhancing reading comprehension, for encouraging and supporting critical conversations about text, and for supporting multicultural education. Such work has the potential of exposing biases embedded in the text and held by the reader and of advancing empathy. These processes can help in stereotype-reduction and deotherizing immigrants and other oppressed groups. Due to the translating demands of moving across semiotic systems, transmediation provides students with opportunities to have conversations over significant nuances of a text and to experience difficult social justice issues through multiple media, which seems to foster spaces where thoughtful, open conversations can be pursued. For such conversations to flourish, however, our findings suggest that it is important for educators to allot ample time and discursive space for engagement with imaginative transmediative activities and to support students through careful questioning.

Today's pre-service teachers are arguably more comfortable with multimodality and movement across sign systems than more experienced teachers; however, they still seem to struggle with utilizing transmediation as a substantive tool for promoting critical literacy. Our findings suggest that, though the pre-service teachers we studied experienced both enhanced comprehension of and critical engagement with literary texts in their coursework, the utilization seemed initially to escape their consciousness and entered their instructional repertoire only after sustained support by the instructor and their peers. This outcome mirrors findings of other research examining efforts to prepare preservice teachers for becoming critical educators, which have reported similarly spotty results (Groenke, 2008; Wolfe, 2010). The pre-service teachers' failure to acknowledge critical analysis of texts in their reflections to the transmediative session, as well as the difficulties they encountered when trying to produce teaching materials fostering critical thinking, may be related to their perceptions and expectations regarding the nature of school learning in general and of literary analysis in particular. Though this study did not involve an examination of the 
pre-service teachers' beliefs, it is reasonable to speculate that the traditional humanistic views of literature often held by teachers (McDiarmid, 1995) and traditional perceptions of teacher roles (Smagorinsky \& Whiting, 1995) may have hindered their ability to effectively conceptualize and ultimately promote critical literacy.

In addition, the difficulties encountered in their instructional planning underscored the dearth of transmediation in schools and seemed to highlight the challenge inherent in this pedagogy in more traditional classrooms. This initial introduction to transmediation as part of their undergraduate curriculum offers pre-service teachers a glimpse of what is possible, but additional support and scaffolding in their teaching practicum and their early teaching careers must be present if this curriculum is to be sustained.

\section{Study Limitations and Implications for Further Research}

In this study we employed a qualitative case study methodology to examine the impact of a series of course experiences related to transmediation on two cohorts of pre-service teachers. The relative small number of participants allowed for the broad collection of rich qualitative data and for the nuanced examination of this case. At the same time, it cannot support generalizability of findings in a quantitative sense. Additional qualitative and quantitative examinations of teacher education settings where similar objectives are pursued could provide further insight into the matter.

Another limitation of this study was the fact that the instructor of the courses involved in this inquiry also acted as one of the researchers. Despite efforts for bracketing, as suggested by Gubrium and Holstein (1997), such a dual role always carries the potential of bias. In addition, we need to acknowledge the possibility of skewed data, since some of the self-reflections collected and analyzed were submitted by study participants as part of a for-credit assignment. Therefore, it is possible that some of the content may have been influenced by their perceptions of the instructor/researcher's expectations.

Finally, we need to note as limitation the fact that we did not follow the pre-service teachers into instructional practice to examine if and how transmediation featured in their teaching. Though such a pursuit was beyond the scope of this study, it is a highly valuable direction that could be pursued in future research. This is particularly important in light of research that suggests that even pre-service teachers who had planned and implemented critical literacy-based instruction did not follow through with the practice when they were no longer required to do so (Wolfe, 2010). 


\section{Conclusion}

In this study we examined the impact of course experiences in transmediation on pre-service teachers' comprehension of and critical engagement with multicultural children's literature, their instructional planning, and their intended practice. Our findings suggest that first-hand experiences with transmediation had a definite positive impact on pre-service teachers' ability to comprehend texts more deeply, to empathize with diverse characters and their backgrounds more intensely, and to realize and value the intellectual challenge of mediating semiotic systems. We also found that recognizing, grasping, and replicating critical engagement with multicultural literature in instructional practice was satisfactorily, but not unequivocally, successful.

These findings suggest that the pedagogical potential of transmediation warrants attention despite the structural challenges of verbocentric, outcomedriven educational systems (as in the United States) and particularly in highly restrictive instructional contexts as those created through scripted instruction. Teacher education programs should address transmediation methodically and comprehensively, make a clear distinction between trivial and substantive transmediations, and provide teachers with sustained support and adequate opportunities to experience, plan, and implement transmediative activities. Otherwise, transmediation is likely to be relegated to the perfunctory "curriculum ornament" status discussed by Siegel (1995) and stay mainly on the fringes of classroom practice. In addition, the findings suggest that it may be productive for teacher educators to engage pre-service teachers in purposeful examinations of their beliefs regarding teacher roles and the nature of knowledge, and to facilitate the inarguably challenging and often personally painful task of recasting their identities as critical educators in a multicultural, multilingual world.

\section{References}

ACARA (Australian Curriculum Assessment and Reporting Authority). (2012). English. Australian Curriculum. Retrieved from http://www.australian curriculum.edu.au/English/

Ahern, K. J. (1999). Ten tips for reflexive bracketing. Qualitative Health Research, 9(3), 407-411.

Akintunde, O. (2007). Multiculturalism and the teacher education experience: Essays on race, class, and culture. Lincoln, NE: iUniverse.

Albers, P., Holbrook, T., \& Harste, J. C. (2010). Talking trade: Literacy researchers as practicing artists. Journal of Adolescent \& Adult Literacy, 54(3), 164-171. Retrieved from: http://globalconversationsinliteracy.files. wordpress.com/2012/05/albersholbrookharste talkingtrade2010.pdf 
Banks, J. A. (2003). Teaching literacy for social justice and global citizenship. Language Arts, 81(1), 18-19.

Beck, A. S. (2005). A place for critical literacy. Journal of Adolescent \& Adult Literacy, 48(5), 392-400. doi:10.1598/JAAL.48.5.3

Black, R. W. (2008). Just don't call them cartoons: The new literacy spaces of anime, manga, and fanfiction. In J. Coiro, M. Knobel, C. L. Lankshear \& D. J. Leu (Eds.), Handbook of Research on New Literacies (pp. 583-610). New York, NY: Lawrence Erlbaum Associates.

Dyson, A. H. (2004). Diversity as a "handful": Toward retheorizing the basics. Research in the Teaching of English, 39(2), 210-214.

Dyson, A. H. (1986). Transitions and tensions: Interrelationships between the drawing, talking, and dictating of young children. Research in the Teaching of English, 20, 379-409.

Dyson, A. H., \& Genishi, C. (2005). On the case. New York, NY: Teachers College Press.

Exley, B., \& Mills, K. A. (2012). Parsing the Australian English curriculum: Grammar, multimodality and cross-cultural texts. The Australian Journal of Language and Literacy, 35(2), 192-205.

Gubrium, J. F., \& Holstein, J. A. (1997). The new language of qualitative method. New York, NY: Oxford University Press.

Groenke, S. L. (2008). Missed opportunities in cyberspace: Preparing preservice teachers to facilitate critical talk about literature through computermediated communication. Journal of Adolescent \& Adult Literacy, 52(3), 224-224-233.

Kellner, D. (2000). New technologies/new literacies: Reconstructing education for the new millennium. Teaching Education, 11(3), 245-265. Retrieved from http://ldt.stanford.edu/ ejbailey/05 MASTERS/MA\%20Articles/kellner ne wtech newlit.pdf

Lewison, M., Flint, A. S., \& Van Sluys, K. (2002). Taking on critical literacy: The journey of newcomers and novices. Language Arts, 79(5), 382-392.

Look, L. (1999). Love as strong as ginger. New York, NY: Atheneum Books for Young Readers.

Loretto, A., \& Chisholm, J. S. (2012). Learning to teach generative meaningmaking through multimodal inquiry. English Teaching: Practice and Critique, 11(1), 136-149.

Lowenstein, K. L. (2009). The work of multicultural teacher education: Reconceptualizing White teacher learners. Review of Educational Research, 79(1), 163-196. 
McDiarmid, G. (1995). Studying prospective teachers' views of literature and teaching literature (Publication No. NCRTL-RR-95-3). East Lansing, MI: National Center for Research on Teacher Learning.

Merriam, S. B. (1998). Qualitative research and case study applications in education. San Francisco, CA: Jossey-Bass Publishers.

Morse, J. M. (1999). Qualitative generalizability. Qualitative Health Research, 9(1), 5-6.

Napoli, M. (2002). Transmediating in the classroom: Implementing critical literacy in elementary grades. In L. Semali (Ed.), Transmediation in the classroom: A semiotics-based media literacy framework (pp. 35-44). New York, NY: P. Lang.

New Zealand Ministry of Education. (2008). How key competencies refocus assessment outcomes. The New Zealand Curriculum Online. Retrieved from: http://nzcurriculum.tki.org.nz/Curriculum-resources/

Nieto, S. (2005). Why we teach. New York, NY: Teachers College Press.

Rief, L. (2003). 100 quickwrites: Fast and effective freewriting exercises that build students' confidence, develop their fluency, and bring out the writer in every student. New York, NY: Scholastic.

Semali, L. (2002). Transmediation: Why study the semiotics of representation? In L. Semali (Ed.), Transmediation in the classroom: A semiotics-based media literacy framework (pp. 1-20). New York, NY: P. Lang.

Semali, L., \& Fueyo, J. (2001, December/January). Transmediation as a metaphor for new literacies in multimedia classrooms. Reading Online, 5(5). Retrieved from http://www.readingonline.org/newliteracies/ lit index.asp?HREF=semali2/index.html

Serafini, F. (2010). Reading multimodal texts: Perceptual, structural and ideological perspectives. Children's Literature in Education, 41, 85-104.

Shor, I. (1997). What is critical literacy? Retrieved from http://newhavenleon.org/ yahoo_site_admin/assets/docs/OutreachWhat_is_critical_literacy__shor.13071914.pdf

Short, K. G., Kauffman, G., \& Kahn, L.H. (2000). "I just need to draw": Responding to literature across multiple sign systems. The Reading Teacher, 54(2), 160-171.

Siegel, M. (2006). Rereading the signs: Multimodal transformations in the field of literacy education. Language Arts, 84(1), 65-77.

Siegel, M. (1995). More than words: The generative power of transmediation for learning. Canadian Journal of Education, 20(4), 455-475.

Smagorinsky, P., \& Whiting, M.E. (1995). How English teachers get taught: Methods of teaching the methods class. Urbana, IL: NCTE. 
Stake, R. E. (1995). The art of case study research. Thousand Oaks, CA: Sage Publications.

Stein, P. (2000). Rethinking resources: Multimodal pedagogies in the ESL classroom. TESOL Quarterly, 34(2), 333-336.

Suhor, C. (1984). Towards a semiotics-based curriculum. Journal of Curriculum Studies, 16(3), 247-57.

Tierney, R. J. (2009). Shaping new literacies research: Extrapolations from a review of the Handbook of Research on New Literacies. Reading Research Quarterly, 44(3), 322-339.

Tierney, R. J., Bond, E., \& Bresler, J. (2006). Examining literate lives as students engage with multiple literacies. Theory into Practice, 45(4), 359-367.

Webb, W. (1961). The choice of the problem. American Psychologist. 16, 223227.

Whitin, P. (2006). Forging pedagogical paths to multiple ways of knowing. English Education, 38(2), 123-145.

Winters, K. (2010). Quilts of authorship: A literature review of multimodal assemblage in the field of literacy education. Canadian Journal for New Scholars in Education, 3(1), 1- 12.

Wolfe, P. (2010). Preservice teachers planning for critical literacy teaching. English Education, 42(4), 368-390.

Yin, R. K. (2012). Applications of case study research. Thousand Oaks, CA: SAGE.

Young, B. (2004). Hannah is my name: A young Immigrant's story. Somerville, MA: Candlewick Press. 